\title{
Serine/Threonine-Protein Kinase TAO3
}

National Cancer Institute

\section{Source}

National Cancer Institute. Serine/Threonine-Protein Kinase TAO3. NCI Thesaurus. Code C106220.

Serine/threonine-protein kinase TAO3 (898 aa, 105 kDa) is encoded by the human TAOK3 gene. This protein is involved in both serine/threonine phosphorylation and mitogen-activated kinase signaling pathway regulation. 